\title{
Diet Intervention Study through Telemedicine Assistance for Systemic Nickel Allergy Syndrome Patients during the COVID-19 Pandemic
}

\author{
Eleonora Nucera ${ }^{1,2,+}$, Angela Rizzi ${ }^{1,+}{ }^{+}$, Raffaella Chini ${ }^{1,+}$, Sara Giangrossi ${ }^{3}$, Franziska Michaela Lohmeyer ${ }^{4}$, \\ Giuseppe Parrinello $^{1}$ D, Tania Musca ${ }^{3}$, Giacinto Abele Donato Miggiano ${ }^{2,3}$, Antonio Gasbarrini ${ }^{2,5}$ \\ and Riccardo Inchingolo $6, *$ (i)
}

1 UOSD Allergologia e Immunologia Clinica, Dipartimento Scienze Mediche e Chirurgiche, Fondazione Policlinico Universitario A. Gemelli IRCCS, 00168 Roma, Italy; eleonora.nucera@policlinicogemelli.it (E.N.); angela.rizzi@policlinicogemelli.it (A.R.); raffaella.chini01@gmail.com (R.C.); p.giuseppe@email.it (G.P.)

2 Medicina e Chirurgia Traslazionale, Università Cattolica del Sacro Cuore, 00168 Roma, Italy; gmiggiano@libero.it (G.A.D.M.); antonio.gasbarrini@unicatt.it (A.G.)

3 UOC Nutrizione Clinica, Dipartimento Scienze Mediche e Chirurgiche, Fondazione Policlinico Universitario A. Gemelli IRCCS, 00168 Roma, Italy; sara.giangrossi@virgilio.it (S.G.); tania.musca@unicatt.it (T.M.)

4 Direzione Scientifica, Fondazione Policlinico Universitario A. Gemelli IRCCS, 00168 Roma, Italy; franziskamichaela.lohmeyer@policlinicogemelli.it

5 UOC Gastroenterologia, Dipartimento Scienze Mediche e Chirurgiche, Fondazione Policlinico Universitario A. Gemelli IRCCS, 00168 Roma, Italy

check for updates

Citation: Nucera, E.; Rizzi, A.; Chini R.; Giangrossi, S.; Lohmeyer, F.M.; Parrinello, G.; Musca, T.; Miggiano, G.A.D.; Gasbarrini, A.; Inchingolo, R. Diet Intervention Study through Telemedicine Assistance for Systemic Nickel Allergy Syndrome Patients during the COVID-19 Pandemic. Nutrients 2021, 13, 2897. https:// doi.org/10.3390/nu13082897

Academic Editor: Armin Alaedini

Received: 31 May 2021

Accepted: 20 August 2021

Published: 23 August 2021

Publisher's Note: MDPI stays neutral with regard to jurisdictional claims in published maps and institutional affiliations.

Copyright: (c) 2021 by the authors. Licensee MDPI, Basel, Switzerland. This article is an open access article distributed under the terms and conditions of the Creative Commons Attribution (CC BY) license (https:/ / creativecommons.org/licenses/by/ $4.0 /)$.
6 UOC Pneumologia, Dipartimento Scienze Mediche e Chirurgiche, Fondazione Policlinico Universitario A. Gemelli IRCCS, 00168 Roma, Italy

* Correspondence: riccardo.inchingolo@policlinicogemelli.it; Tel.: +39-06-3015-6062

+ These authors contributed equally to this work.

Abstract: Background: Restrictions due to the COVID-19 pandemic limited patients' access to hospital care. The aims of this study were to assess dietary nutritional status, quality of life (QoL), and adherence to dietary therapy before and after 30-day personalized diet therapy through telenutrition tools in patients with systemic nickel allergic syndrome (SNAS). Methods: Each SNAS patient underwent the following allergological procedures: (a) face-to-face visit (nutritional visit and QoL evaluation) with prescription of one out of five personalized and balanced dietary plans different for calorie intake, (b) video call visit for dietary evaluation and assessment of adherence to diet after 15 days, and (c) video call visit for dietary and QoL evaluation and assessment of adherence to diet therapy after 30 days (end of study). Results: We enrolled 20 SNAS patients. After 15 and 30 days, we found a statistically significant improvement in anthropometric findings after diet therapy, a significant adherence rate to low-nickel diet (60\% and $80 \%$, respectively), and an improvement in QoL with an increase in almost all psychometric indices. Conclusions: Our study demonstrates that telenutrition can be a valid tool to monitor nutritional status and adherence to balanced low-Ni diet positively affecting QoL in SNAS patients during the COVID-19 pandemic.

Keywords: telemedicine; telenutrition; COVID-19; food allergy; systemic nickel allergy syndrome; balanced diet; nickel; quality of life

\section{Introduction}

Nickel (Ni), an omnipresent metal and a nutritionally important element, commonly causes allergic contact dermatitis (ACD), affecting nearly $8-19 \%$ of adults and $8-10 \%$ of children and adolescents in Europe, with a relevant female predominance [1].

A subset of Ni-ACD patients (about 20\%) also develops a more severe form of disease called systemic nickel allergy syndrome (SNAS) [2,3], with cutaneous and extra-cutaneous involvement (primarily of the gastrointestinal tract), especially after consumption of Ni-rich plant foods [4], and with cutaneous manifestations even in sites without direct contact $[5,6]$. 
Many studies have demonstrated that a significant percentage of SNAS patients improve when placed on a low-Ni diet [4,7-9], an effective diagnostic tool and an important first-line non-pharmacological therapeutic measure.

However, it is extremely difficult to follow a restrictive diet and it is socially discriminating. In fact, a low-Ni diet is relatively low in fiber, essential elements, and vitamins, with potentially significant repercussions on the nutritional status, and therefore on the patient's lifestyle. Furthermore, it is difficult to follow for long periods, especially for those patients who are simultaneously affected by other gastrointestinal comorbidities such as celiac disease or lactose intolerance, all conditions requiring the dietary exclusion of other basic foods (such as milk and its derivatives, dairy products, and vegetables) from the usual dietary regime. All of this can lead to a strong negative impact on patients' quality of life (QoL) [10,11].

The first example of a balanced diet was proposed by Braga et al. [4]. Researchers developed a specific diet designed to reduce daily Ni-intake under $50 \mu \mathrm{g} /$ day, within a caloric intake of $2000 \mathrm{kcal} /$ day for men and $1700 \mathrm{kcal} /$ day for women [4]. This approach has moved beyond the classic concept of an elimination diet based on avoiding a predetermined list of forbidden foods.

Recently, QoL of the world's population has been heavily impacted by the coronavirus disease 2019 (COVID-19) pandemic [12,13].

COVID-19, a contagious disease caused by severe acute respiratory syndrome coronavirus 2 (SARS-CoV-2), was first identified in Wuhan, China, in December 2019. The subsequent spread global disease led to the ongoing pandemic [14]. SARS-CoV-2 infection is characterized by heterogeneity of symptoms. In fact, the infection can be asymptomatic, generate moderate-severe symptoms (interstitial pneumonia, dyspnoea, hypoxia), determine critical symptoms (respiratory failure, shock, or multi-organ dysfunction) [15-17].

From the beginning of the pandemic, Italy, similar to other countries in the world, has implemented preventive measures, which include physical or social distancing, and quarantining, in addition to general hygiene recommendations such as ventilation of indoor spaces, covering coughs and sneezes, hand washing, and keeping unwashed hands away from the face. Social distancing (also known as physical distancing) was introduced with the aim to slow the spread of the disease by minimising close contact between individuals, and many patients also limited their accesses to hospital care and visits of physicians $[18,19]$.

In this context, "telemedicine" can have a fundamental role because it allows continuing visits to monitor patients remotely. The World Health Organization (WHO) defines "telemedicine" as "the delivery of health care services, where distance is a critical factor, by all health care professionals using information and communication technologies for the exchange of valid information for diagnosis, treatment and prevention of disease and injuries, research and evaluation, and for the continuing education of health care providers, all in the interests of advancing the health of individuals and their communities" [20].

In the dietary nutritional field, telemedicine specifically includes "tele-nutrition". The Academy of Nutrition and Dietetics defines "tele-nutrition" as the interactive use of electronic information and telecommunication technologies to implement the Nutrition Care Process (determination, diagnosis, intervention/plan of care, monitoring and nutritional evaluation) carried out remotely [21]. Recently, a step-by-step approach to launch an "electronic nutrition clinic" was proposed for the first time by Farid [22].

Telenutrition could be a crucial tool to remotely monitor and support SNAS patients subjected to restricted and repetitive diets.

The aims of this study were (a) to investigate dietary nutritional status (primary outcome) and, (b) to assess QoL and adherence to dietary therapy (secondary outcomes) of SNAS patients before and after personalized diet therapy through telenutrition tools at the time of the COVID-19 pandemic. 


\section{Materials and Methods}

\subsection{Study Design}

We performed a prospective, single-centre, observational study enrolling SNAS patients in order to investigate their dietary nutritional status and QoL, before and after 30-day personalized diet therapy, and adherence to low-nickel diet, through telenutrition tools, during the COVID-19 pandemic.

\subsection{Setting}

The study was performed at the Allergology Unit and Dietetics and Clinical Nutrition Unit of the Fondazione Policlinico Universitario A. Gemelli IRCCS in Rome, Italy. The study was conducted and described according to the STROBE checklist. The Ethics Committee of the Fondazione Policlinico Universitario A. Gemelli IRCCS in Rome, Italy, approved the "Diet Intervention Study through Telemedicine Assistance on SNAS Patients during the COVID-19 PandEmic-DISTANCE Study" (ID 3448; Prot. N. 0040443/20, NCT04894331). All enrolled patients signed an informed consent form for participation in the study.

\subsection{Participants}

We enrolled patients with (a) history of SNAS (coexistence of typical cutaneous and gastrointestinal symptoms); (b) positive nickel-patch test; (c) clinical improvement of at least $70 \%$ from baseline after 4 weeks of low-Ni diet excluding all foods with a high content of $\mathrm{Ni}(\mathrm{Ni} 100 \mu \mathrm{g} / \mathrm{kg}-\mathrm{Ni}>500 \mu \mathrm{g} / \mathrm{kg}$ ), following BraMa-nickel-diet [3,4]; (d) positivity of a double-blind placebo-controlled oral nickel challenge (DBPCO).

Exclusion criteria included (a) age $<18$ years and $>65$ years; (b) other organic gastrointestinal diseases, such as peptic ulcer, inflammatory bowel diseases, celiac disease, gastrointestinal infections, and small intestinal bacterial overgrowth; (c) diabetes mellitus; (d) hepatic, renal or cardiac dysfunction; (e) thyroid disease or tumor; (f) concomitant treatment with steroids and/or antihistamines in the previous 4 weeks; (g) pregnancy and lactation; (h) smoking, abuse of alcohol, coffee, tea, and cola intake, and (i) inability to give written informed consent.

From 8 October to 30 November 2020, consecutively enrolled patients underwent a pre-diet face-to-face visit (time $0, \mathrm{~T} 0$ ), completed a 30 -day personalized diet, and then underwent a follow-up remote visit through video call (time 2, T2). A further video call was performed 15 days after the start of the diet therapy treatment (time 1, T1).

The study used the commercially available online platform Microsoft Teams, which is included in the Fondazione Policlinico Universitario A. Gemelli IRCCS's Microsoft Office 365 package.

\subsection{Variables}

We selected two primary outcome measurements (dietary assessment and anthropometric data) to evaluate dietary nutritional status of SNAS patients. Moreover, we adopted a Short-Form 36-Item Health Survey (SF-36v2) questionnaire as tool to evaluate QoL (secondary outcome). Finally, adherence to diet therapy (secondary outcome) was investigated through video call at T1 and T2.

\subsection{Measurement}

Study procedures:

T0 face-to-face visit:

- Dietary assessment included nutritional history and eating habits collecting daily and weekly nutritional information with subsequent recommendation to change any incorrect eating habits.

- Collection of anthropometric data: weight, height, body mass index (BMI), and body circumferences (wrist, arm, waist, and hips) [23].

- QoL evaluation. Each patient answered the SF-36v2 (Italian version) questionnaire. It comprises 36-items measuring eight dimensions of general QoL: physical functioning 
(10 items), role limitation due to physical health problems (4 items), bodily pain

( 2 items), general health perceptions (5 items), vitality (4 items), social functioning

( 2 items), role limitations due to emotional problems ( 3 items), and general mental health (5 items). Question scores were coded, summed up, and transformed to a scale of 0 (worst possible health state measured by the questionnaire) to 100 (best possible health state) [24].

At the end of the visit, each patient received a personalized diet that took into account not only the Ni content of the foods (Table 1), but also nutritional status, body composition, basal metabolic rate, and energy needs. Furthermore, patients were asked to avoid the use of stainless-steel utensils to reduce $\mathrm{Ni}$ contamination during cooking.

Table 1. Nickel-rich Foods.

\begin{tabular}{|c|c|c|c|}
\hline $\mathrm{Ni} 100 \mu \mathrm{g} / \mathrm{Kg}$ & $\mathrm{Ni} 200 \mu \mathrm{g} / \mathrm{Kg}$ & $\mathrm{Ni} 500 \mu \mathrm{g} / \mathrm{Kg}$ & $\mathrm{Ni}>500 \mu \mathrm{g} / \mathrm{Kg}$ \\
\hline Carrots & Apricots & Artichoke & Almonds \\
\hline Figs & Broccoli & Asparagus & Chickpeas \\
\hline Lettuce & Corn & Beans & Cocoa \\
\hline Green Salad & Lobster & Cabbage & Concentrated Tomato \\
\hline Liquorice & Onions & Cauliflower & Lentils \\
\hline Mushrooms & Pears & Green Beans & Oats \\
\hline Plaice and Cod & Raisins & Integral Flour & Peanuts \\
\hline Rhubarb & & Yeast & Walnuts \\
\hline \multirow[t]{8}{*}{ Tea } & & Margarine & \\
\hline & & Mussels & \\
\hline & & Oysters & \\
\hline & & Potatoes & \\
\hline & & Peas & \\
\hline & & Plums & \\
\hline & & Spinach & \\
\hline & & Tomatoes & \\
\hline
\end{tabular}

The nutritionist prescribed one of five dietary plans, different only for energy intake (1400-1600-1800-2000-2100 Kcal/day) depending on personal energy needs. The energy requirement was calculated on basal metabolic rate (BMR) of the patient according to Harris and Benedict's [25] and Schofield's [26] formulas. We chose an average between the two results and, subsequently, multiplied this average value by patient's physical activity level (PAL). All dietary plans included foods with low-nickel content.

T1 video call visit:

- Dietary assessment: collection of anthropometric data.

- Assessment of adherence to dietary therapy through question "How many days a week did you adhere to the prescribed dietary treatment?" Two possible mutually exclusive answers: $(1)<5$ days a week, $(2) \geq 5$ days a week.

- $\quad$ T2 video call visit:

- Dietary evaluation: collection of anthropometric data.

- Assessment of adherence to the dietary treatment.

- QoL evaluation.

Figure 1 illustrates the flow-chart of the study.

\subsection{Statistical Analysis and Sample Size}

Given the purely observational nature of the study, no a priori hypotheses were formulated; therefore, a formal calculation of the sample size was not performed. A minimum number of 20 patients to be enrolled was defined.

The sociodemographic and clinical characteristics of the studied population were reported as means and standard deviations for continuous variables and as frequencies and percentages for categorical variables. The chi-squared test was used to evaluate the relationship between frequency of physical activity and BMI. A two-tailed paired Student's 
t-test was used to compare anthropometric findings at T0, T1, and T2 and changes of SF-36 psychometric indices after low-nickel diet (T2 versus T0). A $p$ value $<0.01$ was considered significant. Statistical analysis was performed using the IBM Statistical Package for the Social Sciences (SPSS) version 16.0.

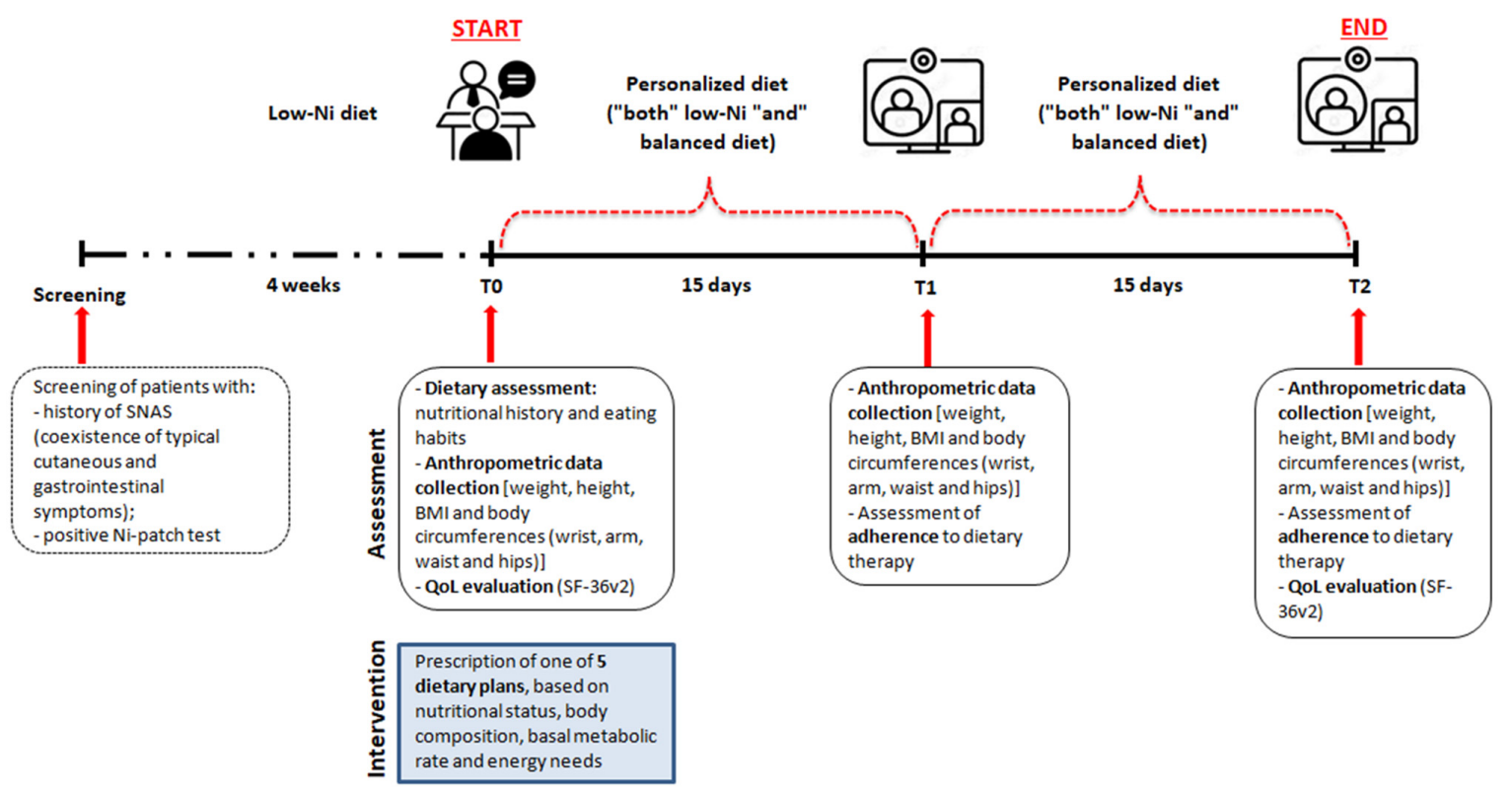

Figure 1. Flow-chart of the study.

\section{Results}

\subsection{Participants}

Twenty-five patients affected by SNAS were screened in this study. Five participants who did not complete all planed follow-up visits online were excluded.

Baseline participants' characteristics are reported in Table 2.

Table 2. Baseline characteristics of patients suffering from SNAS during COVID-19 pandemic.

\begin{tabular}{cccc}
\hline & $\mathbf{N}^{\circ}$ of Patients & 20 \\
\hline Sex & male $/$ female & $1 / 19$ \\
Age [years] & mean $( \pm \mathrm{SD})$ & $41( \pm 8)$ \\
\hline Weight $[\mathrm{Kg}]$ & mean $( \pm \mathrm{SD})$ & $61( \pm 8)$ \\
Height [cm] & mean $( \pm \mathrm{SD})$ & $165( \pm 6)$ \\
AnI $\left[\mathrm{Kg} / \mathrm{m}^{2}\right]$ & mean $( \pm \mathrm{SD})$ & $23( \pm 3)$ \\
& mean $( \pm \mathrm{SD})$ & $15( \pm 1)$ \\
& wrist circumference $[\mathrm{cm}]$ & mean $( \pm \mathrm{SD})$ & $29( \pm 4)$ \\
& arm circumference $[\mathrm{cm}]$ & mean $( \pm \mathrm{SD})$ & $77( \pm 8)$ \\
& waist circumference $[\mathrm{cm}]$ & mean $( \pm \mathrm{SD})$ & $99( \pm 8)$ \\
& hips circumference $[\mathrm{cm}]$ & mean $( \pm \mathrm{SD})$ & $1( \pm 0)$ \\
\hline & waist and hips circumference ratio & $\mathrm{n}(\%)$ & $13(65)$ \\
& Gastro-intestinal symptoms & $\mathrm{n}(\%)$ & $2(10)$ \\
& Cutaneous symptoms & $\mathrm{n}(\%)$ & $2(10)$ \\
Respiratory symptoms & $\mathrm{n}(\%)$ & $9(45)$ \\
& Defecation: Regular & $\mathrm{n}(\%)$ & $7(35)$ \\
Clinical findings & $\mathrm{n}(\%)$ & 0 \\
& Diarrheal & $\mathrm{n}(\%)$ & $4(20)$ \\
& Mixed & $\mathrm{n}(\%)$ & 0 \\
& Chewing problems & $\mathrm{n}(\%)$ & $3(15)$ \\
\hline
\end{tabular}


Table 2. Cont.

\begin{tabular}{cccc}
\hline & $\mathbf{N}^{\circ}$ of Patients & & $\mathbf{2 0}$ \\
\hline & Physical activity: & & \\
& $0-1$ day/week & $\mathrm{n}(\%)$ & $12(60)$ \\
& $2-3$ day/week & $\mathrm{n}(\%)$ & $5(25)$ \\
Life-style data & $>3$ day/week & $\mathrm{n}(\%)$ & $3(15)$ \\
& Smoking & $\mathrm{n}(\%)$ & $2(10)$ \\
& Alcohol & $\mathrm{n}(\%)$ & $13(65)$ \\
& Particular diet & $\mathrm{n}(\%)$ & 0 \\
\hline
\end{tabular}

The majority of patients were females (95\%) and $41 \pm 8$ years old. The assessment of each patient revealed that $55 \%$ of patients were normal weight (average BMI $23 \pm 3 \mathrm{~kg} / \mathrm{m}^{2}$; BMI $\geq 18.5 \mathrm{~kg} / \mathrm{m}^{2}$ and $\left.\leq 24.9 \mathrm{~kg} / \mathrm{m}^{2}\right), 25 \%$ overweight (BMI $>25 \mathrm{~kg} / \mathrm{m}^{2}$ ), and $20 \%$ underweight $\left(\mathrm{BMI}<18.5 \mathrm{~kg} / \mathrm{m}^{2}\right)$.

When asked about the most common self-reported symptoms, $65 \%$ of participants reported gastro-intestinal disturbances, especially swelling and bloating, even if defecation was described as regular in almost half of the study group. Conversely, cutaneous and respiratory complaints were rarely reported. Three $(15 \%)$ patients described swallowing problems, while no patient reported chewing disorders.

Moreover, Table 2 shows that $60 \%$ of the participants were not at all or 1 day a week engaged in physical activity during the COVID-19 pandemic.

The weekly frequency of physical activity was related to BMI values $(p=0.0276$, chi-squared test, Figure 2). Only normal weight subjects reported regular physical activity.

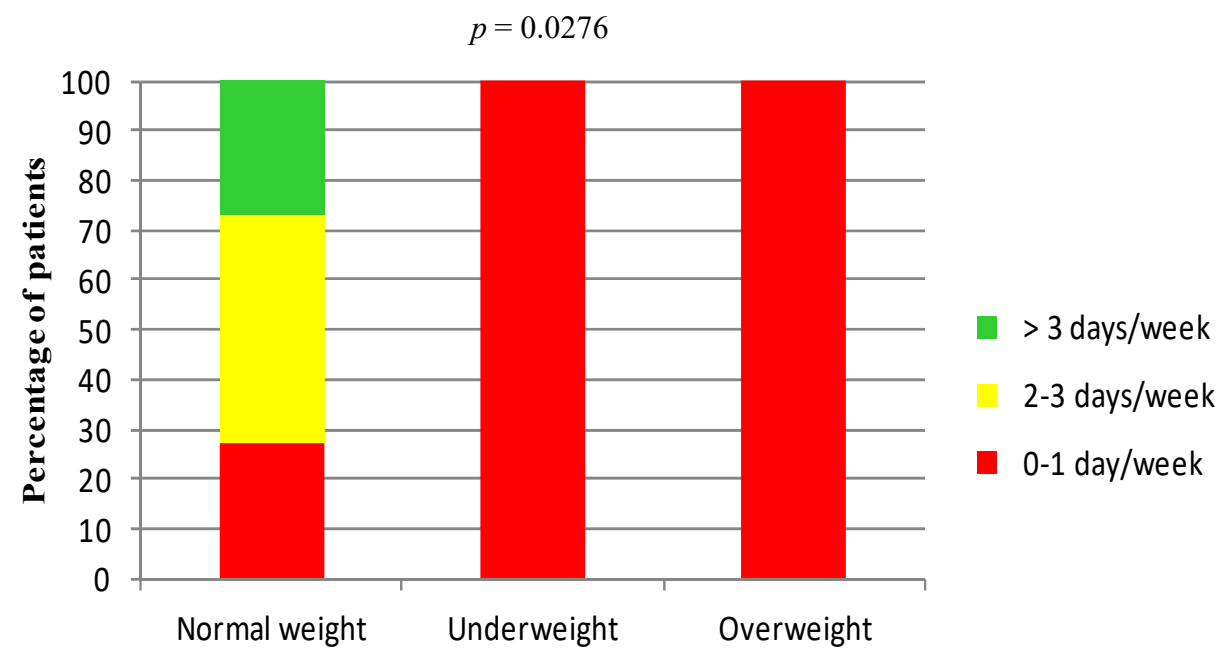

Stratification of patients according BMI

Figure 2. Relationship between frequency of physical activity and BMI. Patients are stratified according to BMI values into three group: normal weight $\left(18.5-24.9 \mathrm{~kg} / \mathrm{m}^{2}\right)$, underweight $\left(\mathrm{BMI}<18.5 \mathrm{~kg} / \mathrm{m}^{2}\right)$, and overweight $\left(\mathrm{BMI}>24.9 \mathrm{~kg} / \mathrm{m}^{2}\right)$. Chi-squared test.

Finally, regarding lifestyle, a considerable number of participants drank alcohol, but no patient followed a particular diet, such as vegetarian, vegan, or raw food.

\subsection{Dietary Behaviours}

Table 3 presents the eating habits of the study participants during the COVID-19 pandemic.

Results showed that $50 \%$ patients ate $4-5$ meals a day and $70 \%$ of them at the same time; $95 \%$ preferred their home as place for lunch on weekdays. Moreover, patients reported rarely eating outside home (1-2 times a week). Concerning water intake, only $10 \%$ of participants consumed at least $2 \mathrm{~L}$ per day during the pandemic. 
Table 3. Dietary behaviours at baseline of SNAS patients during COVID-19 pandemic.

\begin{tabular}{|c|c|c|c|}
\hline Behaviours & Frequencies/Places/Amounts & $\mathbf{N}^{\circ}$ of Patients & $\%$ \\
\hline \multirow[t]{3}{*}{$\mathrm{N}^{\circ}$ of meals/day } & $2-3$ & 6 & 30 \\
\hline & $4-5$ & 10 & 50 \\
\hline & $>5$ & 4 & 20 \\
\hline \multirow{2}{*}{$\begin{array}{l}\text { Are main meals eaten } \\
\text { at the same time? }\end{array}$} & Yes & 14 & 70 \\
\hline & No & 6 & 30 \\
\hline \multirow{7}{*}{$\begin{array}{l}\text { Lunch on } \\
\text { NON-holidays }\end{array}$} & At home & 19 & 95 \\
\hline & In a company canteen & 0 & 0 \\
\hline & In a school or kinder garden canteen & 0 & 0 \\
\hline & In a restaurant, trattoria, diner & 0 & 0 \\
\hline & In a bar & 0 & 0 \\
\hline & In the workplace & 0 & 0 \\
\hline & At the home pf parents, relatives, friends & 1 & 5 \\
\hline \multirow{4}{*}{$\begin{array}{l}\text { Eat away from home } \\
\text { (times/week) }\end{array}$} & Never & 2 & 10 \\
\hline & $1-2$ & 11 & 55 \\
\hline & $2-3$ & 5 & 25 \\
\hline & $>3$ & 2 & 10 \\
\hline \multirow[t]{4}{*}{ Water } & $<1 / 2 \mathrm{~L}$ & 2 & 10 \\
\hline & $1 / 2-1 \mathrm{~L}$ & 11 & 55 \\
\hline & $1-2 \mathrm{~L}$ & 5 & 25 \\
\hline & $>2 \mathrm{~L}$ & 2 & 10 \\
\hline
\end{tabular}

The frequency of consumption for particular food products during the COVID-19 pandemic are presented in Figure 3.

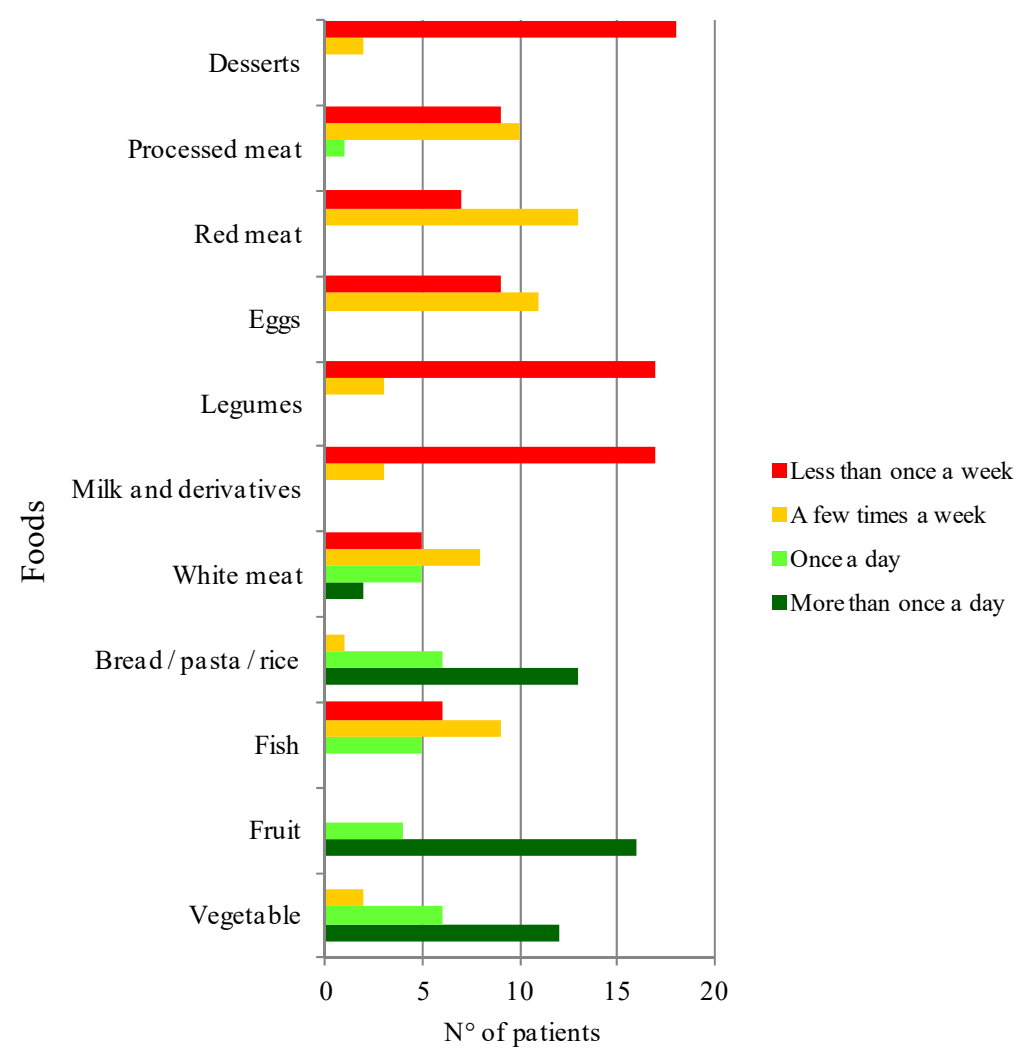

Figure 3. The frequency of consumption of foods during COVID-19 pandemic in the study group of patients with SNAS. 
Overall, patients reported healthy eating habits in terms of frequent consumption (at least once a day) of vegetables, fruit, and whole-grain foods (bread/pasta/rice) and concomitant low consumption (few times or less than once a week) of desserts and red and processed meat. Eighty-five percent of enrolled patients did not consume milk and dairy products. Likewise, eighty-five percent of patients did not consume legumes.

\subsection{Impact of Diet on Anthropometric Findings: Telenutrition Data}

When examining the impact of diet therapy on anthropometric findings (weight, BMI, circumference of wrist, arm, waist, and hips, and waist and hip circumference ratio) after 15 and 30 days (T1 and T2, respectively), all mean values of indices showed a statistically significant reduction after diet therapy, except for BMI at T2, wrist circumference and waist and hip circumference ratio (Table 4, two-tailed paired Student's $t$-test: T1 versus T0 and $\mathrm{T} 2$ versus $\mathrm{T} 1$, respectively).

Table 4. Anthropometric findings at baseline, after 15 days and at the end of the study.

\begin{tabular}{|c|c|c|c|c|c|c|}
\hline & & T0 (Baseline) & $\begin{array}{c}\mathrm{T} 1 \\
\text { (after } 15 \text { Days) }\end{array}$ & $\begin{array}{c}\mathrm{T} 2 \\
\text { (after } 30 \text { Days) }\end{array}$ & $\begin{array}{c}p \text { Value } \\
\text { (T1 vs. T0) * }\end{array}$ & $\begin{array}{c}p \text { Value } \\
(\mathrm{T} 2 \text { vs. T1) * }\end{array}$ \\
\hline weight $[\mathrm{Kg}]$ & mean $( \pm S D)$ & $61.2( \pm 8.1)$ & $60.4( \pm 7.7)$ & $59.6( \pm 7.0)$ & 0.0096 & 0.0116 \\
\hline $\mathrm{BMI}\left[\mathrm{kg} / \mathrm{m}^{2}\right]$ & mean $( \pm S D)$ & $22.5( \pm 3.4)$ & $22.0( \pm 3.0)$ & $221.9( \pm 2.8)$ & 0.0003 & NS \\
\hline wrist circumference $[\mathrm{cm}]$ & mean $( \pm S D)$ & $15.4( \pm 1.0)$ & $15.4( \pm 1.1)$ & $15.4( \pm 1.0)$ & NS & NS \\
\hline arm circumference $[\mathrm{cm}]$ & mean $( \pm S D)$ & $28.8( \pm 3.7)$ & $27.7( \pm 3.0)$ & $27.0( \pm 2.3)$ & 0.0508 & 0.0068 \\
\hline waist circumference $[\mathrm{cm}]$ & mean $( \pm S D)$ & $77.1( \pm 8.6)$ & $76.1( \pm 7.3)$ & $74.5( \pm 6.4)$ & 0.0375 & 0.0001 \\
\hline hips circumference $[\mathrm{cm}]$ & mean $( \pm \mathrm{SD})$ & $99.3( \pm 8.2)$ & $98.0( \pm 7.6)$ & $96.5( \pm 6.6)$ & 0.0009 & 0.0012 \\
\hline $\begin{array}{l}\text { waist and hip } \\
\text { circumference [cm] }\end{array}$ & mean $( \pm S D)$ & $1( \pm 0)$ & $1( \pm 0)$ & $1( \pm 0)$ & NS & NS \\
\hline
\end{tabular}

SD, standard deviation; BMI, body mass index; NS, non-significant. *: The comparison among anthropometric data at baseline (T0), after 15 days and after 30 days of low nickel diet; $p<0.05$ (two-tailed paired Student's $t$-test: T1 versus T0 and T2 versus T1, respectively).

\subsection{Adherence to Low-Nickel Diet}

We explored the adherence rate to low-nickel diet using a dedicated questionnaire through telenutrition during the COVID-19 pandemic. Already after 15 days of treatment, the adherence rate, defined by at least 5 days a week of treatment with a low-nickel diet, was significant ( $60 \%$ of the sample). The rate increased after 30 days of treatment, reaching $80 \%$ (Figure 4 ).

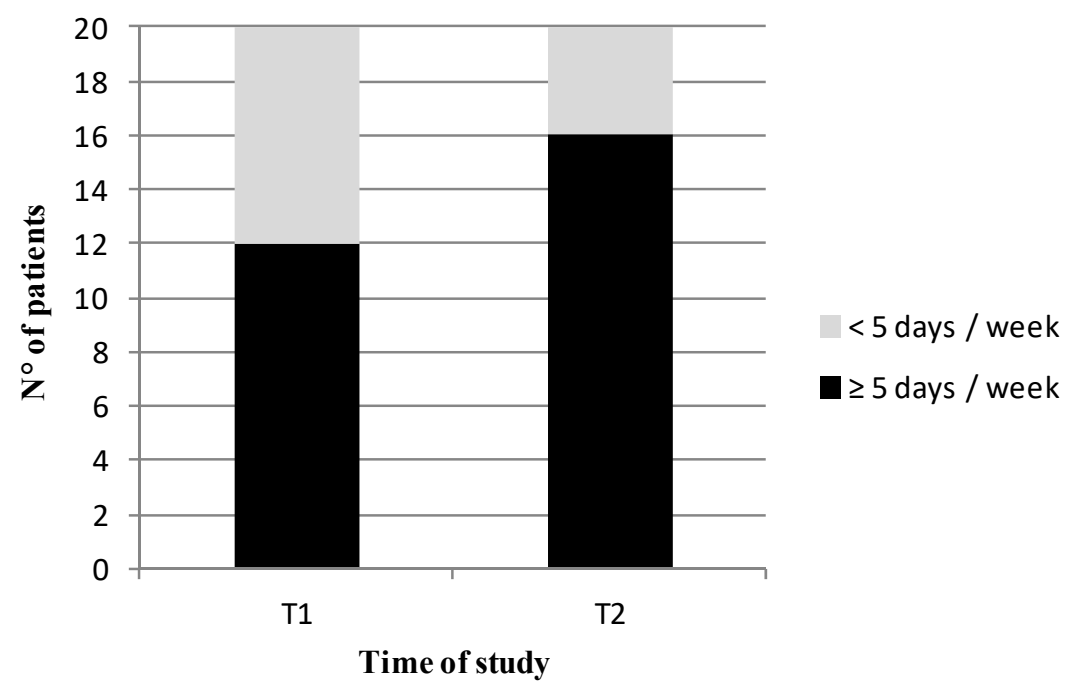

Figure 4. Patients' adherence to low-nickel diet. Adherence was defined by the number of days per week of low-Nickel diet ( $\geq 5$ days/week) and was evaluated after 15 days (T1) and at the end of the study (after 30 days, i.e., T2). 


\subsection{Impact of Low-Nickel Diet on QoL of Patients with SNAS during the COVID-19 Pandemic}

The low-nickel diet determined a QoL improvement already after 30 days of treatment. In fact, a trend of increase in almost all psychometric indices with statistically significant change for the general health scale (average pre-diet: $38 \pm 10$, average post-diet: $54 \pm 8$; $p=0.0000$ ), vitality scale (average pre-diet: $49 \pm 17$, average post-diet: $58 \pm 5 ; p=0.0242$ ) and physical component summary (average pre-diet: $48 \pm 6$, average post-diet: $53 \pm 6$; $p=0.0369$, two-tailed paired Student's $t$-test) was observed (Figure 5).

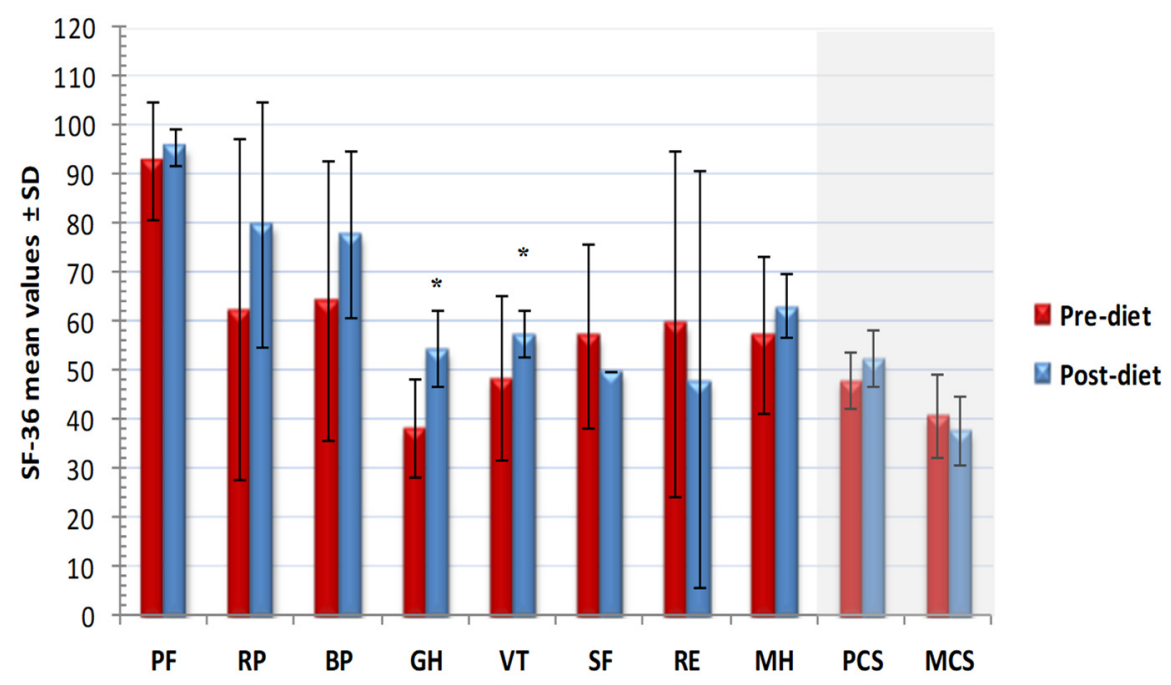

Figure 5. Changes of short form 36 items health survey (SF-36) psychometric indices after low nickel diet. PF, physical function; RP, role-physical; BP, bodily pain; GH, general health; VT, vitality; SF, social function; RE, role-emotional; $\mathrm{MH}$, mental health; PCS, physical component summary; MCS, mental component summary; $: p<0.05$ (two-tailed paired Student's $t$-test).

\section{Discussion}

In this pilot study, we demonstrated that telenutrition could be a valid tool to monitor nutritional status, adherence to balanced low-nickel diet positively affecting QoL in an Italian population of patients with SNAS during the COVID-19 pandemic.

To date, telenutrition and counselling interventions, as part of the health care program, have a strong impact on health status in terms of weight reduction, hemoglobin A1C, blood pressure, and serum lipids $[21,27,28]$. However, to the best of our knowledge, no previous study focused on telenutrition to evaluate the dietary nutritional status of SNAS patients and literature on telenutrition as tool to provide clinical support during the COVID-19 pandemic is still scarce. Surprisingly, no study focused on the use of e-health tools in the management of patients with food allergy, growingly considered as a public health burden and defined as the "second wave" of the allergy epidemic, following asthma $[29,30]$.

For decades, food elimination has been the cornerstone of food allergy management. Although immune-modulatory treatments are increasingly used, most patients have yet to rule out one or more culprit foods with potential repercussions on nutritional status [31]. This risk is amplified in SNAS patients due to the ubiquitous nature of the metal and the resulting multiple food restrictions in diet regimens [32], which further compromises QoL $[11,33]$.

Our study, carried out on a predominantly female population, as expected from the literature $[1,32,34]$, showed that the weekly frequency of physical activity of the SNAS patients was related to BMI values. Moreover, only normal weight subjects reported regular physical activity.

In 2015, Lusi et al. found a surprisingly high prevalence of Ni sensitization in overweight women with metabolic syndrome. The low-Ni diet, adopted by researchers, significantly reduced BMI [32]. 
The "stay-at-home" measure, one of the most common preventive measures adopted by many countries as part of the fight against COVID-19, is potentially related to a change in people's lifestyle, exercise habits, and diet [35].

Our results enrich the growing literature on the relationship between nutrition status and exercise behaviours during the COVID-19 pandemic. In fact, recently, Özden and Parlar Kiliç examined the effect of social isolation on nutrition and exercise behaviours of nursing students and found that nearly half of students gained weight and the majority did not exercise regularly [36]. In the same period, Deschasaux-Tanguy and colleagues explored changes in dietary intake, physical activity, body weight, and food supply in a large French population highlighting reduction of physical activity in $53 \%$ of studied cohort [37]. Similarly, an international online survey, launched in April 2020, confirmed the negative effect of the COVID-19 home confinement on physical activity [35].

Furthermore, we observed preserved healthy eating habits in terms of number of meals per day (most patients ate at least four meals a day), taking main meals at the same time of the day (reported by $70 \%$ of participants) and frequency of consumed foods. In particular, we observed high consumption (at least once a day) of "healthy foods" as vegetables, fruit and whole-grain foods and concomitant low consumption (few times or less than once a week) of "unhealthy foods" as desserts, red and processed meat. The consumption of milk and dairy products and legumes were extremely rare. Instead, previous studies highlighted a trend towards unhealthy eating habits during the COVID-19 pandemic. In particular, a cross-sectional study in the United Arab Emirates [38], Middle East, and North Africa region by Cheikh et al. showed a progressive distance from the Mediterranean diet [39]. More recently, Radwan et al. investigated the prevalence and determinants of unhealthy behaviour changes during the COVID-19 lockdown among United Arab Emirates. Increased food intake, especially salty and sweet snacks, was the most common unhealthy behaviour reported by $31.8 \%$ of participants [40]. In our study, the attitude towards healthy eating behaviours could probably derive also from SNAS patients' awareness that dietary interventions are crucial in controlling symptoms due to oral intake of high-nickel foods [9].

Regarding the impact of low-nickel diet, we found an improvement in almost all anthropometric indices already after 15 days. Recently, Tárraga López et al. explored the usual dietary pattern prior to confinement and assessed the adherence to the Mediterranean diet in 490 Spanish adults without evidence of clinically relevant changes in body composition [41]. A recent Italian online survey by Maffoni et al. demonstrated a slight but significant increase in BMI during the COVID-19 pandemic and stratification by lifestyle changes revealed a significant variation in BMI: negative lifestyle changes were correlated with increased BMI and positive lifestyle changes with decreased BMI [42]. It is reasonable to assume that the positive impact of our dietary intervention could depend on the significant adherence rate found after only 15 days, reaching $80 \%$ after 1 month of diet.

This study has few limitations. First, it was monocentric. Second, the number of patients was limited partially due to highly selective inclusion/exclusion criteria. Finally, the period of the study (30 days) could influence the generalizability of our results.

Despite these limitations, this study found evidence that telenutrition may allow for monitoring of nutritional status, adherence to a balanced low-nickel diet, and positively affecting QoL in SNAS patients during the COVID-19 pandemic. Furthermore, it confirms the positive effect of low-nickel diet on QoL of SNAS patients [11], as demonstrated with improved physical (general health and physical component summary) and mental health (vitality) domain scales.

This pandemic has caused and continues to cause nutritional and behavioral imbalances, undermining both health and longevity of the world population. One of the possible countermeasures of health systems could be the integration of telemedicine tools in the routine management of patients. This "both/and" approach would allow pursuing a personalized medicine-nutrition strategy also in these contexts. To achieve these goals, 
future larger trials are needed on how to combine telemedicine and face-to-face visits to optimize the management of food allergy and improve health-related outcomes.

Author Contributions: Conceptualization, E.N., A.R., R.I.; methodology, A.R. and R.I.; formal analysis, R.I.; investigation, R.C., S.G., G.P. and T.M.; data curation, A.R.; writing-original draft preparation, A.R., R.C., F.M.L. and R.I.; supervision, E.N., G.A.D.M. and A.G. All authors have read and agreed to the published version of the manuscript.

Funding: This research received no external funding.

Institutional Review Board Statement: The study was conducted according to the guidelines of the Declaration of Helsinki, and approved by the Ethics Committee of the Fondazione Policlinico Universitario A. Gemelli IRCCS in Rome, Italy (ID 3448; Prot. N. 0040443/20, 7 October 2020). The study protocol was registered at ClinicalTrials.gov (NCT04894331).

Informed Consent Statement: Informed consent was obtained from all subjects involved in the study.

Data Availability Statement: Data sharing is not applicable to this article.

Conflicts of Interest: The authors declare no conflict of interest.

\section{References}

1. Ahlström, M.G.; Thyssen, J.P.; Wennervaldt, M.; Menné, T.; Johansen, J.D. Nickel allergy and allergic contact dermatitis: A clinical review of immunology, epidemiology, exposure, and treatment. Contact Dermat. 2019, 81, 227-241. [CrossRef] [PubMed]

2. Ricciardi, L.; Arena, A.; Arena, E.; Zambito, M.; Ingrassia, A.; Valenti, G.; Loschiavo, G.; D'Angelo, A.; Saitta, S. Systemic Nickel Allergy Syndrome: Epidemiological Data from Four Italian Allergy Units. Int. J. Immunopathol. Pharmacol. 2014, $27,131-136$. [CrossRef] [PubMed]

3. Di Gioacchino, M.; Ricciardi, L.; De Pità, O.; Minelli, M.; Patella, V.; Voltolini, S.; Di Rienzo, V.; Braga, M.; Ballone, E.; Mangifesta, R.; et al. Nickel oral hyposensitization in patients with systemic nickel allergy syndrome. Ann. Med. 2013, 46, 31-37. [CrossRef]

4. Braga, M.; Quecchia, C.; Perotta, C.; Timpini, A.; Maccarinelli, K.; Di Tommaso, L.; Di Gioacchino, M. Systemic Nickel Allergy Syndrome: Nosologic Framework and Usefulness of Diet Regimen for Diagnosis. Int. J. Immunopathol. Pharmacol. 2013, 26, 707-716. [CrossRef] [PubMed]

5. Jensen, C.S.; Menne, T.; Johansen, J.D. Systemic contact dermatitis after oral exposure to nickel: A review with a modified meta-analysis. Contact Dermat. 2006, 54, 79-86. [CrossRef] [PubMed]

6. Grieco, T.; Faina, V.; Alei, L.; Dies, L.; Milana, M.; Calvieri, S. Systemic contact dermatitis (SCD) due to dietary nickel. Clin. Ter. 2012, 163, 127-128.

7. Veien, N.K.; Hattel, T.; Laurberg, G. Low nickel diet: An open, prospective trial. J. Am. Acad. Dermatol. 1993, $29,1002-1007$. [CrossRef]

8. Lombardi, F.; Fiasca, F.; Minelli, M.; Maio, D.; Mattei, A.; Vergallo, I.; Cifone, M.G.; Cinque, B.; Minelli, M. The Effects of Low-Nickel Diet Combined with Oral Administration of Selected Probiotics on Patients with Systemic Nickel Allergy Syndrome (SNAS) and Gut Dysbiosis. Nutrients 2020, 12, 1040. [CrossRef]

9. Rizzi, A.; Nucera, E.; Laterza, L.; Gaetani, E.; Valenza, V.; Corbo, G.M.; Inchingolo, R.; Buonomo, A.; Schiavino, D.; Gasbarrini, A. Irritable Bowel Syndrome and Nickel Allergy: What Is the Role of the Low Nickel Diet? J. Neurogastroenterol. Motil. 2017, 23, 101-108. [CrossRef]

10. Pizzutelli, S. Systemic nickel hypersensitivity and diet: Myth or reality? Eur. Ann. Allergy Clin. Immunol. 2011, 43, 5-18.

11. Rizzi, A.; Di Rienzo, A.; Buonomo, A.; Aruanno, A.; Carusi, V.; Ricci, A.G.; Centrone, M.; Mezzacappa, S.; Romeo, L.; Schiavino, D.; et al. Impact of nickel oral hyposensitization on quality of life in systemic nickel allergy syndrome. Int. J. Immunopathol. Pharmacol. 2020, 34. [CrossRef] [PubMed]

12. Shek, D.T.L. COVID-19 and Quality of Life: Twelve Reflections. Appl. Res. Qual. Life 2021, 16, 1-11. [CrossRef] [PubMed]

13. Amdal, C.D.; Pe, M.; Falk, R.S.; Piccinin, C.; Bottomley, A.; Arraras, J.I.; Darlington, A.S.; Hofsø, K.; Holzner, B.; Jørgensen, N.M.H.; et al. Health-related quality of life issues, including symptoms, in patients with active COVID-19 or post COVID-19; a systematic literature review. Qual. Life Res. 2021, 19, 1-15. [CrossRef]

14. Lu, H.; Stratton, C.W.; Tang, Y.-W. Outbreak of pneumonia of unknown etiology in Wuhan, China: The mystery and the miracle. J. Med. Virol. 2020, 92, 401-402. [CrossRef]

15. Chen, N.; Zhou, M.; Dong, X.; Qu, J.; Gong, F.; Han, Y.; Qiu, Y.; Wang, J.; Liu, Y.; Wei, Y.; et al. Epidemiological and clinical characteristics of 99 cases of 2019 novel coronavirus pneumonia in Wuhan, China: A descriptive study. Lancet 2020, 395, 507-513. [CrossRef]

16. Huang, C.; Wang, Y.; Li, X.; Ren, L.; Zhao, J.; Hu, Y.; Zhang, L.; Fan, G.; Xu, J.; Gu, X.; et al. Clinical features of patients infected with 2019 novel coronavirus in Wuhan, China. Lancet 2020, 395, 497-506. [CrossRef] 
17. Wang, D.; Hu, B.; Hu, C.; Zhu, F.; Liu, X.; Zhang, J.; Wang, B.; Xiang, H.; Cheng, Z.; Xiong, Y.; et al. Clinical Characteristics of 138 Hospitalized Patients With 2019 Novel Coronavirus-Infected Pneumonia in Wuhan, China. JAMA 2020, 323, 1061-1069. [CrossRef] [PubMed]

18. Lim, J.; Broughan, J.; Crowley, D.; O’Kelly, B.; Fawsitt, R.; Burke, M.C.; McCombe, G.; Lambert, J.S.; Cullen, W. COVID-19's impact on primary care and related mitigation strategies: A scoping review. Eur. J. Gen. Pract. 2021, 27, 166-175. [CrossRef]

19. Jones, D.; Neal, R.D.; Duffy, S.R.G.; Scott, S.E.; Whitaker, K.L.; Brain, K. Impact of the COVID-19 pandemic on the symptomatic diagnosis of cancer: The view from primary care. Lancet Oncol. 2020, 21, 748-750. [CrossRef]

20. World Health Organization. A Health Telematics Policy in Support of WHO's Health-for-All Strategy for Global Health Development. In Proceedings of the WHO Group Consultation on Health Telematics, Geneva, Switzerland, 11-16 December 1997; World Health Organization: Geneva, Switzerland, 1998.

21. Practicing Telehealth for Nutritionists and RDNs. Available online: https://www.eatrightpro.org/practice/practice-resources/ telehealth/practicing-telehealth (accessed on 20 February 2021).

22. Farid, D. COVID-19 and Telenutrition: Remote Consultation in Clinical Nutrition Practice. Curr. Dev. Nutr. 2020, 4, nzaa124 [CrossRef]

23. World Health Organization. Physical Status: The Use and Interpretation of Anthropometry. Report of a WHO Expert Committee; World Health Organization: Geneva, Switzerland, 1995; Volume 854, pp. 1-452.

24. Apolone, G.; Mosconi, P. The Italian SF-36 Health Survey: Translation, Validation and Norming. J. Clin. Epidemiol. 1998, 51, 1025-1036. [CrossRef]

25. Harris, J.A.; Benedict, F.G. A Biometric Study of Human Basal Metabolism. Proc. Natl. Acad. Sci. USA 1918, 4, 370-373. [CrossRef]

26. Schofield, W.N. Predicting basal metabolic rate, new standards and review of previous work. Hum. Nutr. Clin. Nutr. 1985, 39 (Suppl. S1), 5-41. [PubMed]

27. Kelly, J.T.; Reidlinger, D.P.; Hoffmann, T.C.; Campbell, K.L. Telehealth methods to deliver dietary interventions in adults with chronic disease: A systematic review and meta-analysis. Am. J. Clin. Nutr. 2016, 104, 1693-1702. [CrossRef] [PubMed]

28. Huang, J.-W.; Lin, Y.-Y.; Wu, N.-Y. The effectiveness of telemedicine on body mass index: A systematic review and meta-analysis. J. Telemed. Telecare 2018, 25, 389-401. [CrossRef] [PubMed]

29. Loh, W.; Tang, M.L.K. The Epidemiology of Food Allergy in the Global Context. Int. J. Environ. Res. Public Health 2018, 15, 2043. [CrossRef]

30. Prescott, S.; Allen, K. Food allergy: Riding the second wave of the allergy epidemic. Pediatr. Allergy Immunol. 2011, 22, 155-160. [CrossRef]

31. Skypala, I.J.; McKenzie, R. Nutritional Issues in Food Allergy. Clin. Rev. Allergy Immunol. 2019, 57, 166-178. [CrossRef]

32. Lusi, E.A.; Di Ciommo, V.M.; Patrissi, T.; Guarascio, P. High Prevalence of Nickel Allergy in an Overweight Female Population: A Pilot Observational Analysis. PLoS ONE 2015, 10, e0123265. [CrossRef]

33. Perino, A. Nickel and Food. Int. J. Immunopathol. Pharmacol. 2005, 18, 15-17.

34. Thyssen, J.P.; Linneberg, A.; Menné, T.; Johansen, J.D. The epidemiology of contact allergy in the general population-Prevalence and main findings. Contact Dermat. 2007, 57, 287-299. [CrossRef] [PubMed]

35. Ammar, A.; Brach, M.; Trabelsi, K.; Chtourou, H.; Boukhris, O.; Masmoudi, L.; Bouaziz, B.; Bentlage, E.; How, D.; Ahmed, M.; et al. Effects of COVID-19 Home Confinement on Eating Behaviour and Physical Activity: Results of the ECLB-COVID19 International Online Survey. Nutrients 2020, 12, 1583. [CrossRef] [PubMed]

36. Özden, G.; Kiliç, S.P. The Effect of Social Isolation during COVID-19 Pandemic on Nutrition and Exercise Behaviors of Nursing Students. Ecol. Food Nutr. 2021, 21, 1-19. [CrossRef] [PubMed]

37. Deschasaux-Tanguy, M.; Druesne-Pecollo, N.; Esseddik, Y.; de Edelenyi, F.S.; Allès, B.; Andreeva, V.A.; Baudry, J.; Charreire, H.; Deschamps, V.; Egnell, M.; et al. Diet and physical activity during the coronavirus disease 2019 (COVID-19) lockdown (March-May 2020): Results from the French NutriNet-Santé cohort study. Am. J. Clin. Nutr. 2021, 113, 924-938. [CrossRef] [PubMed]

38. Ismail, L.C.; Osaili, T.M.; Mohamad, M.N.; Al Marzouqi, A.; Jarrar, A.H.; Abu Jamous, D.O.; Magriplis, E.; Ali, H.I.; Al Sabbah, H.; Hasan, H.; et al. Eating Habits and Lifestyle during COVID-19 Lockdown in the United Arab Emirates: A Cross-Sectional Study. Nutrients 2020, 12, 3314. [CrossRef] [PubMed]

39. Ismail, L.C.; Osaili, T.M.; Mohamad, M.N.; Al Marzouqi, A.; Jarrar, A.H.; Zampelas, A.; Habib-Mourad, C.; Abu Jamous, D.O.; Ali, H.I.; Al Sabbah, H.; et al. Assessment of eating habits and lifestyle during the coronavirus 2019 pandemic in the Middle East and North Africa region: A cross-sectional study. Br. J. Nutr. 2021, 126, 757-766. [CrossRef]

40. Radwan, H.; Al Kitbi, M.; Hasan, H.; Al Hilali, M.; Abbas, N.; Hamadeh, R.; Saif, E.; Naja, F. Indirect Health Effects of COVID-19: Unhealthy Lifestyle Behaviors during the Lockdown in the United Arab Emirates. Int. J. Environ. Res. Public Health 2021, $18,1964$. [CrossRef]

41. López, P.J.T.; Royo, J.M.P.; Herencia, J.C.; Carro, A.; Rosich, N.; Panisello, M.; Presas, J.A.; Albero, J.S. Changes in adherence to the Mediterranean diet observed in a Spanish population during confinement for the SARS-CoV-2 pandemic. Nutr. Hosp. 2020, 38, 109-120. [CrossRef]

42. Maffoni, S.; Brazzo, S.; De Giuseppe, R.; Biino, G.; Vietti, I.; Pallavicini, C.; Cena, H. Lifestyle Changes and Body Mass Index during COVID-19 Pandemic Lockdown: An Italian Online-Survey. Nutrients 2021, 13, 1117. [CrossRef] 